\title{
Bridging Strategies for VR-Based Learning
}

\author{
Tom Moher \\ Andrew Johnson \\ Electronic Visualization Laboratory \\ EECS Department \\ University of Illinois at Chicago \\ Chicago, IL 60607 USA \\ \{moher, ajohnson\}@eecs.uic.edu
}

\author{
Stellan Ohlsson ${ }^{1}$ \\ Mark Gillingham ${ }^{2}$ \\ ${ }^{1}$ Department of Psychology \\ ${ }^{2}$ College of Education \\ University of Illinois at Chicago \\ Chicago, IL 60607 USA \\ \{Stellan, MarkGill\}@uic.edu
}

\begin{abstract}
A distributed immersive virtual environment was deployed as a component of a pedagogical strategy for teaching third grade children that the Earth is round. The displacement strategy is based on the theory that fundamental conceptual change requires an alternative cognitive starting point which doesn't invoke the features of pre-existing models. While the VR apparatus helped to establish that alternative framework, conceptual change was strongly influenced by the bridging activities which related that experience to the target domain. Simple declarations of relevance proved ineffective. A more articulated bridging process involving physical models was effective for some children, but the multiple representations employed required too much model-matching for others.
\end{abstract}

\section{Keywords}

Learning environments, conceptual change, virtual reality, user models

\section{INTRODUCTION}

The expense and concomitant inaccessibility of immersive virtual reality (VR) technologies has invited skepticism over their value as instructional media, particularly for school-age children. Nonetheless, a growing number of rescarchers [11, 31] have begun to cxplore methods of effective deployment of these technologies in support of learning.

We believe that VR offers potential benefits for some kinds of learning goals. However, the high costs of investigation in this domain imposes special responsibilities on researchers. At the least, we believe that research in VR and learning should be directed toward learning problems which are:

1. important (represented in recognized curricula standards),

2. hard (demonstrably difficult, or resistant to traditional methods),

3. a priori arguably enhanced by VR technologies, and

4. informed by contemporary theory and practice in education, psychology, and cognitive science.

In this paper, we describe an ongoing research project in which immersive VR is deployed as a component of a Permission to make digital or hard copies of all or part of this work for personal or classroom use is granted without fee provided that copics are not made or distributed for profit or commercial advantage and that copies bear this notice and the full citation on the first page. To copy otherwise, to republish, to post on servers or to redistribute to lists. requires prior specific permission andior a fee.

CHI '99 Pittsburgh PA USA.

Copyright ACM 1999 0-201-48559-1/99/05 \$5.00 pedagogical strategy for teaching third grade children that the Earth is round. This goal is well represented in the AAAS Project 2061 Science for all Americans report, and is a standard component of elementary school science curricula.

Perhaps less well known is that this fact, and, more importantly, the implications surrounding it, are not easily accommodated by young learners. A rich body of literature demonstrates that children often react to the assertion that the Earth is round by forming blended mental models conditioned by their prior experience, or even distinct multiple models, in an attempt to incorporate the new information.

In the remaining sections, we argue that the "Round Earth" case is an exemplar of an important problem in learning that involves fundamental conceptual change. We propose a novel strategy-displacement learning-to address that problem, and discuss how VR technologies may be well suited to support that strategy. Finally, we describe an ongoing research project that employs that strategy to address the Round Earth problem, and present empirical evidence of both the potential effectiveness and fragility of its implementation.

\section{A LEARNING PARADOX}

The acquisition of deep ideas might well follow laws other than the learning of either propositions or skills [22]. Briefly put, the acquisition of deep ideas moves from the specific to the abstract, while skill acquisition moves from general methods to increasingly domain-specific: expertise. The vehicle for skill acquisition is deliberate practice [14]; the vehicle of deep learning is reflective exploration.

Fundamental conceptual change encounters a peculiar paradox. The ideas that underpin advanced understanding in different fields are typically more fundamental than the ideas a novice learner might bring into the field from prior experience $[10,20]$. This fact helps explain the puzzling observation that although many deep ideas can be stated in less than a page of text, systematic attempts to teach them nevertheless fail with alarming frequency [6]. Fiducational researchers, particularly in the fields of science and mathematics, have found over and over again that seemingly thoughtful programs for teaching deep ideas can be unsuccessful (e.g., [25]).

This outcome can be understood in terms of one of the central principles of the learning sciences: Existing knowledge is the main tool for understanding new 
experience or new discourse. In other words, both direct experience and discourse (oral or written) is understood by being analyzed in terms of, or assimilated to, existing knowledge structures. For example, a fairy tale is understood by being subsumed under the reader's existing schema or story grammar for fairy tales. This subsumption process operates without difficulty when experience or discourse is congruent with existing organizing ideas. $\Lambda$ narrative of a baseball game, for example, is completely comprehensible to someone who already knows the nature, structure and character of the game. Learning from instructional discourse with a similarly constrained goal is also relatively unproblematic.

However, when either experience or discourse (instructional or otherwise) attempts to communicate a concept that is both different from, and more fundamental than, the learner's existing ideas, a paradox occurs. Although the intent behind the discourse is to replace the learner's existing ideas, those existing ideas are the learner's only tools by which to acquire the new idea $[13,14]$. Research in the cognitive sciences has documented that the typical outcome of this fact is distortion: the novel idea is misunderstood in the process of - and as a byproduct of-being assimilated to prior knowledge.

A simple and compelling example of this effect has heen documented by Nussbaum [21] and by Vosniadou [29] and Vosniadou and Brewer [30]: Young children tend to believe that the Earth is flat. One's concept of the shape of the Earth has profound consequences for one's interpretation of both experience and discourse, so the shift from a flat Earth to a spherical Earth view counts, at an elementary level, as deep learning in our framework. Empirical studies have demonstrated that if children are told that the Earth is round, they often react to the novel information by constructing a mental model of the Earth as a pancake, flat yet round. The intended message is distorted in the process of assimilation to mean that the Earth is circular (rather than spherical).

Although simple (to adults), we suggest that the flat Earth/round Earth case is prototypical of deep conceptual learning that exemplifies the essential features of the learning paradox at any age level: both experience and discourse that attempt to communicate ideas that are deeper or more fundamental than the ideas the learner already has tends to be distorted in the comprehension process, because those prior ideas are the main tools for understanding. This is the learning paradox [4]. Support for deep learning must overcome this paradox.

\section{CIRCUMVENTING THE LEARNING PARADOX}

If the learning paradox is real, how is anything new ever learned? A transformational account assumes that new knowledge is created via operations on prior knowledge. Prior knowledge serves as raw material, and new knowledge is the result of generalization, specialization or some other type of cognitive operation, applied to that raw material.

One example of a transformational approach is the classical induction hypothesis: knowledge is created by extracting commonalities across a set of exemplars or instances. Inductive approaches to learning (sometimes referred to as similarity-based approaches) encounter several unsolved problems, including how to handle exceptions and disjunctions [3]. Another example of a transformational view is the attempt to conceptualize science learning as a form of belief revision, an approach that provides students with evidence to the effect that their intuitive beliefs (sometimes called misconceptions) are false, and that they need to replace them with morc accuratc belicfs (c.g., [17]). Researchers from Piaget [23] to Karmiloff-Smith [19] have tried to explain cognitive development in terms of so-called transition mechanisms [28]. However, there is as yet no widely accepted description of a developmental transition mechanism. In general, any transformational account of cognitive change assumes the existence of powerful transformations that can traverse the space of possible conceptualizations without search.

In contrast, a displacement account of cognitive change assumes that a new understanding of a domain or phenomenon begins by establishing an alternative cognitive starting point, an idea or concept that is established outside the learner's existing system of domain knowledge. Initially, such an alternative representation of the domain might be rudimentary, lack detail and have few concrete examples, justifications or arguments associated with it, and hence be completely dominated by the prior, wellestablished representation. However, over time, all available representations of a domain compete for attentional resources and a representation that is useful in dealing with certain types of situations or problems gradually gains strength and might eventually displace the previous representation. The existence of a compete/evaluate phase allows displacement theories to postulate weaker and hence more plausible operations on prior knowledge than those required by a transformational account. Displacement theories of cognitive change also have support in biology and neuroscience [7].

The displacement framework suggests a particular instructional strategy for supporting deep conceptual learning: fundamental ideas which contrast with the learner's current ideas need to be established on their own terms, so to speak, before they are brought into contact with the learner's prior ideas. In other words, a new idea should not be taught by directly confronting or transforming the learner's current idea, but by establishing an alternative knowledge structure or representation, a cognitive seed out of which a deeper understanding of the relevant domain can grow. After reviewing the evidence related to the learning of so-called ontological categories, Chi [8] reached a similar conclusion: “ ... instruction about a new ontological category must proceed by teaching this new ontological category of concepts independently of the old or existing conceptions." (p. 179) We claim that this conclusion holds not just for ontological categories, but for fundamental concepts in general.

The strategy described so far provides us with considerable power to help learners construct alternative mental representations of particular facets of reality. Although crucial, this is not enough. Our overall strategy dictates a second step: eventually, the alternative representation must 
be brought into contact with the learner's prior knowledge of the domain and absorb or subsume it. Unless learners eventually bring their experience in the displaced domain into contact with everyday experience in the target domain, the learning objective is not reached. The last tactic in our educational strategy is therefore to help the learner interface their new ideas with their prior knowledge. We call activities that aim to do this bridging activities. Cognitive research on analogy $[9,15,18]$ provide a rich theoretical basis for the design of bridging activities.

\section{THE ASTEROID WORLD}

In an attempt to apply these principles to the round earth problem, we constructed a distributed, immersive VR environment that allowed children to explore a smalldiameter asteroid. Two distinct interfaces were provided: at any given time, one child was in a CAVE (a three meter cube with rear-projected head-tracked stereo video on three walls and a floor) and the other seated at an ImmersaDesk (a single rear-projected stereo video display approximately the size of a drafting table).

The child in the CAVE (the astronaut) was situated on the virtual asteroid surface (Figure 1), and navigated using three buttons on a hand-held wand to move left, right, or forward. (Usability tests employing an isometric thumb joystick were disastrous!) Astronauts were charged with collecting fuel cells (through a proximity trigger) scattered about the surface of the asteroid in order to enable the marooned space ship to return to Earth.

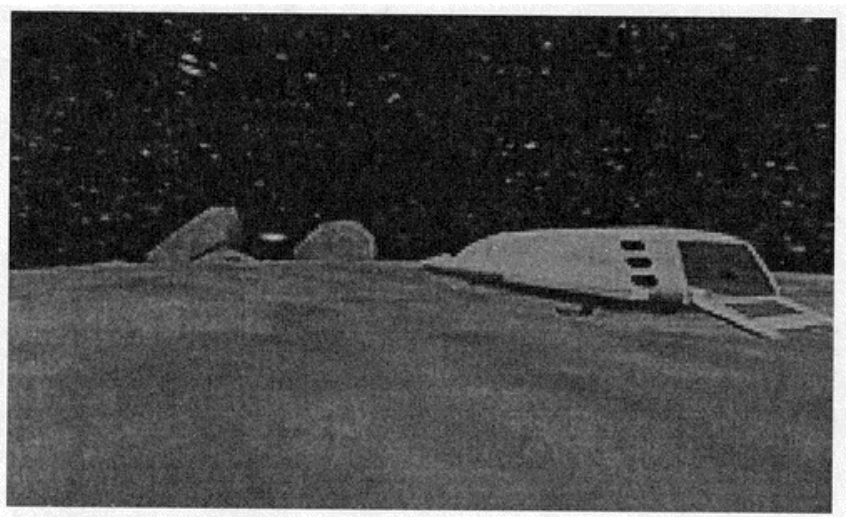

Figure 1. The astronaut/CAVE view of the asteroid. The space ship sits at the North Pole.

The child at the ImmersaDesk (the mission controller) was afforded a view of the asteroid from somewhere out in space, along with a direct video feed of the astronaut's view (Figure 2). Mission control used an isometric thumb joystick to rotate and tilt the view of the asteroid, and was charged with directing the astronaut (represented by an avatar on the asteroid) toward available fuel cells. An audio link connects the two users, and additional audio cues ate provided when fuel cells are acquired, and when time limits are approaching.

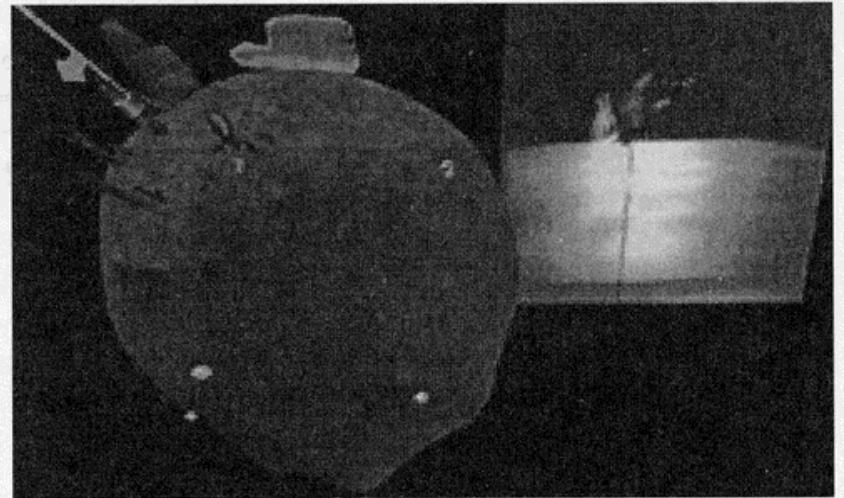

Figure 2. The Mission Controller/ImmersaDesk view of the asteroid. The mission controller simultaneously sees the avatar of the astronaut moving around the spherical asteroid and the view from the astronaut's perspective of the slightly rounded surface of the asteroid.

\section{PILOT STUDY 1}

A great deal of component knowledge is subsumed under the rubric of "knowing that the Earth is round," We prepared a 16-item questionnaire (inspired by the items used in $[29,30])$ designed to probe for understanding of the following concepts (see Appendix):

1. that the Earth is (roughly) spherical in shape,

2. that there is no absolute "up" or "down" associated with a particular portion of the Earth,

3. that the Earth is continuous and circumnavigable, and

4. that the horizon is a curved edge which may partially or totally occlude objects on the other side (or in space).

Subjects were drawn from a local Chicago public elementary school. The children were third grade students who were required to attend summer school because they had scored below the minimum requirement on the Iowa Test of Basic Skills for promotion to the fourth grade.

Individual oral pre-test interviews based on the questionnaire and lasting 15-20 minutes were conducted at .a Chicago public school a day or two prior to their VR experience. Subjects responded to the items with verbal answers, drawings (sometime annotated), gestures, and the construction of PlayDoh models; each assessment was recorded on audio tape.

The children were brought in pairs to a university campus, given a cover story describing the "rescue" scenario, and were given brief training by and adult guide in the use of the VR apparatus. The two distinct interfaces allowed us to employ a tightly coupled "jigsaw" collaboration scheme [2], alternating each child between the two (positively interdependent) roles of astronaut and mission controller. Upon completion of the task, the subjects were brought together in front of the ImmersaDesk for a bridging activity, and an adult interviewer led them through a brief recounting of their experience using the mission controller view as a referent. Each of the four identified knowledge components was reviewed and reinforced in the context of the asteroid, and in each case, the students were told that the 
same facts applied to the Earth as well, citing similarities and differences (size) between the two celestial bodies. Immediately following the bridging activity, the children were brought to a different room, and interviewed separately (post-test) using the same questionnaire. Following completion of the assessment, they were transported back to their school.

Ten children completed the entire protocol. For each subject, the audio tapes and written documents were reviewed for evidence of learning in each of the four component knowledge areas.

The results were disheartening. Where we had hoped that conversation between the children might focus on apparent contradictions to their daily experience (c.g., "hey, you're upside down," "no, I'm not!"), the discourse focused almost exclusively on the mechanics of the apparatus and the nominal goal of collecting fuel cells. Among the ten subjects, four began with highly immature models of the Earth's shape (typically, pancake shapes); of those four subjects, all continued to hold to their naive models in the post-test interviews. The remaining six subjects had indicated a belief in the sphericality of Earth in the pretests, but all fell short on one or more of the remaining knowledge components. Among those six, there was limited improvement in the relativity of up and down questions, and in the circumnavigability questions. Still, the robust outcome we had hoped for was obviously missing.

We called a halt to the first pilot study, and considered the factors that may have led to our limited success. While we were able to identify numerous potential sources (including the design of the application interfaces, novelty effects, learning and attention deficit disorders among our subject pool, social and communications difficulties among subject pairs, and more), we focused on what we believed were the two most important issues: overengagement in the task at the expense of learning, and the failure to bridge learning about the asteroid to the subjects' mental models of Earth.

\section{PILOT STUDY 2}

To address these issues, a second pilot study was conducted, with two important protocol changes. First, the initial "training" period with the VR apparatus was modified so that the adult guide spent several minutes drawing the subjects' attention to salient features of the asteroid which reflected the target knowledge components prior to establishing the nominal task goal. We hoped that this would help to overcome the subjects' overwhelming focus on the mechanics of collecting the fuel cells while at the same time serving as an advance organizer for the target knowledge goals.

Second, we made a significant change in the bridging activity following the VR experience. We built a featurefaithful Styrofoam scale model of the asteroid, and purchased a larger commercial Earth globe. In place of the joint ImmersaDesk debriefing, we substituted individual bridging sessions lasting about 15 minutes for each participant. During those sessions, we systematically reviewed each of the knowledge components, using a discussion to relate the subjects' experience in the VR environment first to the Styrofoam model of the asteroid, then to the Earth globe, citing the analogies between the two physical models. In each case, movable stick-on props and figurines were used to represent VR objects and the participants themselves. Out of concern that the immediacy and nature of the revised bridging activity might lead to surface similarity in the post-test, we delayed the follow-up assessments until the next day, back at the children's school. As it turned out, the discovery nature of the bridging activity itself proved useful in comparing the persistence of apparent learning.

Ten children participated in the second pilot study, drawn from the same subject pool as in the first pilot. There was little direct evidence that the change in the initial training protocol had much effect; the children's dialogues continued to be almost exclusively operational. However, unlike the first pilot, there were some success stories. Among the eight children, seven reflected immature initial (pancake) models; among this group, two appeared to have adopted a spherical model of Earth by the time of the post-test, and a third subject moved to a dual model of Earth in which one component was spherical. In the following, we contrast the experience of an apparently successful learner with one whose post-test interview did not appear to reflect conceptual change.

\section{A Case of Learning Failure}

Ebony is a nine-year old third grader. During her pre-test, Ebony drew a circle to represent the Earth, with land masses scattered around the interior of the circle. Her PlayDoh model of the Earth was shaped like a pancake. When asked what was in the area around the Earth on her drawing, Ebony indicated that there was water "underneath" her circle, and a moon "above" the circle. She indicated that there was an end to the earth, and that an animal could accidentally fall off the end "onto the ground." Ebony responded to the "baskets" question (Appendix, question 15) by insisting that the girls would put balls in each other's baskets. She indicated that the balls would fall through the "shafts" (Appendix, question 16).

Following her VR experience, Ebony was quite animated in her discussion, and operational descriptions of the event dominated her spontaneous discourse. When asked what she did, she responded "I was going around a moon, and it was like a big ball." The interviewer asked again, "Was it more like a pancake, or more like a ball?" Ebony reiterated that it was "like a ball." The interviewer told Ebony that "the Earth is like a ball, too, only larger," with which she appeared to concur, elaborating with "and heavier, too." The interviewer asked Ebony what would happen if you were on the asteroid and you kept walking, to which she responded "You would fall off but she [her VR partner] didn't fall" because "she was kinda like stuck." After the interviewer had indicated that the same phenomenon would hold on the Earth, he asked why people in Australia didn't fall off. She answered that "They don't walk on the globe."

In her post-test the following day, Ebony was still quite excited about the VR experience, and continued to discuss the operational characteristics of the controls. She noted 
that (at the ImmersaDesk) "you move the ball around" to the operational characteristics of the controls. She noted that (at the ImmersaDesk) "you move the ball around" to help direct her friend. She answered the decontextualized up/down questions correctly (Appendix, questions 1, 2), but when asked to build a PlayDoh model of the Earth, she produced a pancake shape, indicating that the "bottom" of the pancake was where oceans, lakes, rivers, and the beach were located. When asked directly whether her shape was more like a pancake or a ball, Ebony replicd "a pancake." The interviewer asked her whether she remembered talking about the shape of the Earth the day before ("Yes") and asked what he had told her, to which she replied "The Earth is round, almost like a ball. And the green stuff is like Earth, and the blue stuff is like the sea." Ebony continued to believe that there was an end of the Earth (Appendix, questions 9,10), and that if you walked past, you would fall "into the mountains or something, or the hills, or far away." Asked why she didn't fall off when she was on the asteroid, she replied "Cause I was an astronaut and it was like I was glued on." Ebony's drawing of Earth continue to have a strict orientation (moon on top, circular Earth in the middle, lakes and oceans on the bottom). Her response to the horizontal shaft question, unlike on the pre-test, had the ball falling toward the bottom of the page.

\section{A Case of Conceptual Change}

Celandra is also a nine-year-old third grade student. During her pre-test, Celandra held that up and down were absolute for all people on the Earth, and made a circular drawing to reflect the Earth's shape, with people living "all over" the interior of the circle. Her PlayDoh model was pancakeshaped, with people living "only on the top." Celandra reported that people couldn't see things far away "because it's too far and it might be cloudy." She answered the airplane question (Appendix, question 7) by saying that the airplane would go to the end of the Earth, where it was "very cold and it would be like different people." An animal could accidentally fall off the Earth, into a "big open space...under the ground." 'The sun and moon were sometimes not visible because they "went to another planet" or were "behind some clouds." Celandra's basket (Figure 3) and shafts pictures reflected an absolute notion of up and down.

When asked what she had done in the VR experience, Celandra gave a strictly operational response, describing the number of fuel cells collected and the interaction with her partner. When asked the shape of the asteroid, she said it was "like a ball" rather than a pancake, and expressed strong agreement that the Styrofoam model was like the asteroid. Celandra said that the space surrounding the Styrofoam model was filled with stars. She indicated that if you continued to walk around the asteroid, "you'd end up back to the space ship again, but on a different side [of the ship]." When asked the same question regarding the Earth, she believed that she would return to Chicago, where she started. Celandra felt that during her VR experience it felt like she might fall off the asteroid, but she didn't, because "it's a round ball," and that people on the south pole of Earth wouldn't fall off, either.

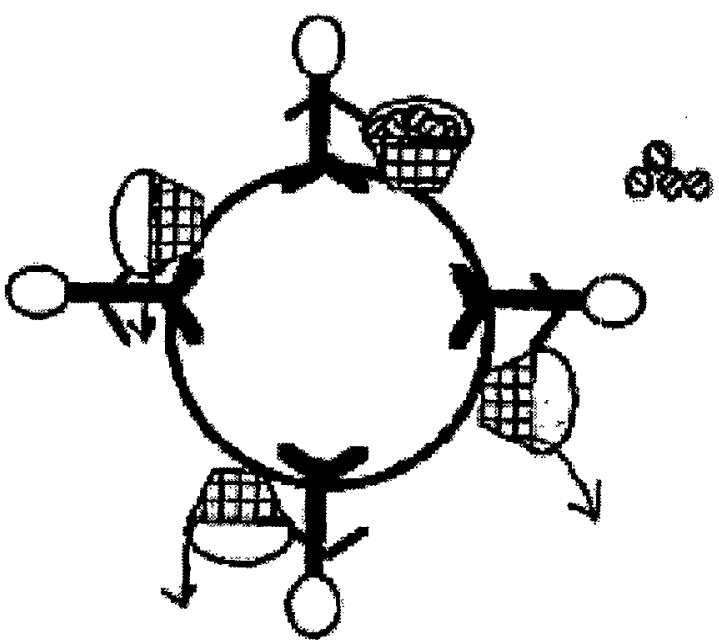

Figure 3. Celandra's balls falling out of the baskets during her pre-test; down is always toward the bottom of the page.

During her post-test, Celandra believed that up and down were relative to where you were on Earth, and that "up" in China was not the same as "up" in Chicago "because the earth is like a ball and people who are down up under the earth then they won't fall off." She pointed over her head when asked where "down" was for people in China. In contrast to her pre-test, Celandra created a sphere for her PlayDoh Earth model, and indicated that people live "up here and down here," pointing to both northern and southern hemispheres. She couldn't see where a cannon ball lands on the other side of the Earth, she said, because "it's blocked. Cuz the earth is just round and it's like a ball and it's blocked by the ball."

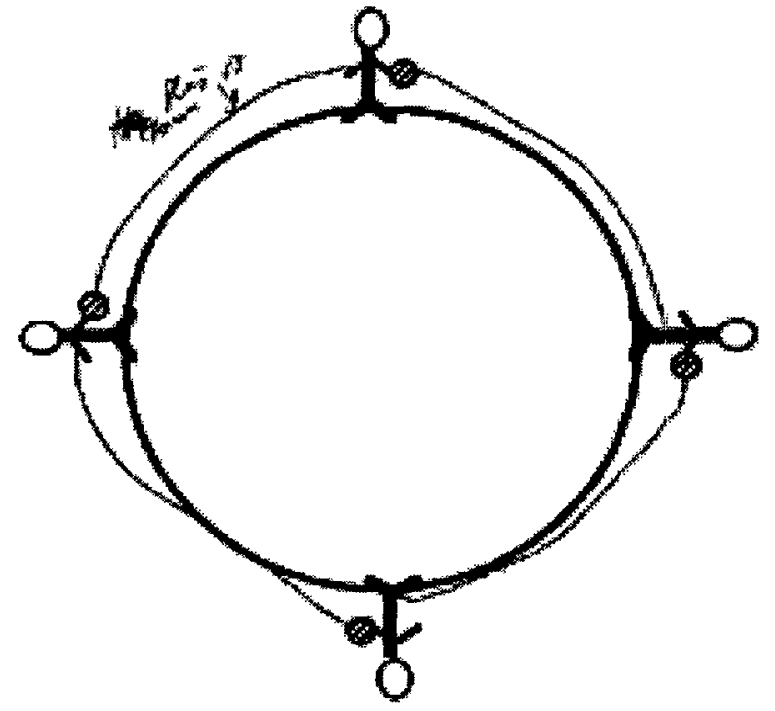

Figure 4. Celandra's balls falling "down" during her posttests; down is clockwise in the figure.

Flying straight for a long time in an airplane would take her back to Chicago, she stated, and she would never get to the cnd of the Earth because "it's a round ball." People couldn't fall off the Earth because "people live up and down, 
and [pointing to the South Pole of her PlayDoh model] down is up for them." She continued to believe that the moon and the sun became invisible because of clouds or their movement to other planets. The space surrounding her PlayDoh model was filled with "stars," but the space surrounding her (circular) drawing of Earth was tilled with "oceans." Celandra's shaft models were correct in both orientations; the released balls picture (Figure 4) at first appeared incorrect, but she explained that the labeled arc was "down" to the person on the left side of the circle.

\section{Analysis}

To Ebony, the VR experience was engaging, but appeared to have little effect on her model of the Earth. Her observation that her friend should have fallen of the asteroid, but didn't, along with her feeling of being "glued on," indicated that she believed the VR representation to be unrealistic. She readily accepted that the shape of the VR and Styrofoam asteroids were spherical ("like a ball"), and concurred that the shape of the Earth globe was also spherical. Ebony's response that Australians didn't fall off the Earth because "they don't walk on the globe" indicated to us that she viewed the Earth globe and the Earth as distinct (unrelated) objects. This was reinforced during her post-test, when she created a pancake PlayDoh model of Earth, then replied to the interviewer's question about the prior day's experience by describing the Earth as a blue and green ball-a clear reference to the globe.

Celandra, in contrast, appeared to undergo a fundamental conceptual change, from a flat pancake with an ominous "end" to a spherical body where up and down were relative to position. Her model was not perfect--there were still oceans outside her drawing of Earth, and while she understood occlusion for Earth-bound objects, she didn't use the same reasoning for other celcstial bodics. Nonetheless, she appeared to understand that what she had learned about the asteroid also now applied to her Earth as well.

\section{DISCUSSION}

While immersive VR is sometimes derided as a technology in search of application, it provides visualization and interaction features which appear to hold promise for learning applications. Salzman, et. al. [26] cite three promising features of VR with respect to learning: threedimensional immersion, multiple frames of reference, and multisensory cues. Our asteroid environment utilizes all three of these VR features.

Was the VR experience an integral part of the learning for our subjects? For those subjects who appeared to undergo conceptual change, we believe that it was effective in helping to establish an "alternative cognitive starting point," as required by the displacement learning model. Unlike Ebony, who continued to hold a "separate reality," these subjects found the asteroid a plausible reality, and were able to use their experience to subsequently reason about how things might be on Earth.

But accepting the VR asteroid as plausible was not enough. Subjects in both pilot studies who appeared to find the asteroid believable did not successfully bridge their knowledge to the target domain. For subjects in pilot study
1 , we believe that the fault lay in the abruptness of the intended bridging activity, and that simply telling them that their new knowledge applied to Earth left them too tools with which to bridge between two apparently dissimilar representations.

The pilot study 2 subjects who succeeded in changing their concept of Earth did so, we believe, because the revised bridging procedures afforded them an articulated chain of representations from source to target domain, with each new representation being sufficiently similar to its predecessor to be accepted.

The "long path back" didn't work for everyone in pilot study 2 ; we still had more failures than successes. Here, a reasonable interpretation might be that revising the bridging procedure introduced too many intermediate representations, and that the cognitive demands were simply too great for the subjects to handle [1]. (After all, these children had to deal with six distinct external representations: two versions of the VR asteroid, the Styrofoam asteroid model, the Earth globe, their 2-D drawings, and their PlayDoh models.)

It is not new news that transfer of learning does not always occur, and the issue as to when, and under which circumstances, it does occur, remains an unresolved (and perpetually engaging) problem $[16,24,27]$. In the context of programming systems, there has been a great deal of evidence demonstrating the difficulty of transfer (e.g., [5]) between representations.

VR is good at delivering multiple, even believable, representations, and in so doing, seems an attractive medium for displacement learning strategies. If the representations used are too far from the target domain, however, they run the risk of being viewed as a separate reality. If they are too numerous, they run the risk of overwhelming the learner in feature matching.

At a time when even the phrase virtual reality has no consensus definition, it is implausible that decontextualized results demonstrating its generalized efficacy as a learning medium are even achievable. The important job for researchers interested in VR-based learning environments is to find workable balances among available technologies, learning goal, users' developmental stage, interaction designs, social settings, and a host of other factors, which demonstrate promise- not proofs-of concept.

Our discussion has avoided altogether the most decontextualized aspect of the work reported: its locus. We used real school children, but we did it (for the most part) in an unreal setting-a one-shot experience in a university laboratory. We are currently working with teachers at a local public elementary school in planning a multi-year deployment of VR technologies within an established curriculum structure. We hope to be able to report more evidence concerning the use of VR and displacement learning, including a revisiting of the Round Earth problem, based on that experience.

\section{ACKNOWLEDGMENTS}

We wish to thank Shirley Woodard, Program Director of South Loop Elementary School in Chicago, IL, and her 
third grade students, for their enthusiastic participation in the Round Earth project. Joe Alexander, Carlos Orrego, Maria Roussos, Mike Tolio, Jospephine Anstey, Jim Costigan, Tom Frisch, Jason Leigh, Dave Pape, and Tom DeFanti were instrumental to the application design, development, and support. Jyoti Jain, Mark Orr, Josh Hemmerich, and Elaine Ohlsson assisted in the development and application of the assessment interviews.

This research was supported by funding from the National Science Foundation award EIA 9720351, supported by NSF awards CDA-9303433, CDA-9512272, NCR-9712283, CDA-9720351, and the NSF ASC Parnerships for Advance Computational Infrastructure program. The CAVE and ImmersaDesk are trademakrs of the Board of Trustees of the University of Illinois.

\section{REFERENCES}

1. Ainsworth, S., Bibby, P.A., \& Wood, D.J. (1997). Information technology and multiple representations: New opportunities-new problems. Journal of Information Technology for Teacher Education, 6, 93104.

2. Aronson, E., Blaney, N., Stephan, C., Sikes, J., \& Snapp, M. (1978). The Jigsaw Classroom. Bcverly Hills, CA: Sage.

3. Angluin, D., \& Smith, C. H. (1983). Inductive inference: Theory and methods. Computing Surveys, 15, 237-269.

4. Bereiter, C., (1985). Toward a solution of the learning paradox. Review of Educational Research, 55, 201-226.

5. Bonar, J. \& Cunningham, R. (1988). Bridge: Tutoring the programming process. In J. Psotka, L. Massey, and S. Mutter (Eds.), Intelligent tutoring systems: Lessons learned (pp. 409-434). Hillsdale, NJ: Lawrence Erlbaum.

6. Bruer, J. T. (1994). Schools for thought: A science of learning in the classroom. Cambridge, MA: MIT Press.

7. Calvin, W. H. (1996). The cerebral code. Cambridge, MA: MIT Press.

8. Chi, M. T. H. (1992). Conceptual change within and across ontological categories: Examples from learning and discovery in science. In R. N. Giere, (Ed.), Cognitive models of science (pp. 129-186). Minneapolis, Minnesota: University of Minnesota Press.

9. Clement, J. (1988). Observed methods for generating analogies in scientific problem solving. Cognitive Science, 12, 563-586.

10. Confrey, J. (1990). A review of research on student conceptions in mathematics, science, and programming. In C. B. Cazdan, (Ed.), Review of research in education (Vol. 16, pp. 3-56). Washington, DC: American Educational Research Association.

11. Dede, C., Salzman, M., \& Loftin, R. (1996) ScienceSpace: Virtual Realities for Learning Complex and Abstract Scientific Concepts. In Proceedings VRAIS' '96 (pp.246-253).
12. DiSessa, A. A. (1988). Knowledge in pieces. In G. Forman \& P. Pufall, (Eds.), Constructivism in the computer age (pp. 49-70). Hillsdale, NJ: Erlbaum.

13. DiSessa, A. A. (1993). Toward an epistemology of physics. Cognition and Instruction, 10, 105-225.

14. Ericsson, K. A., Krampe, R. Th., \& Tesch-Romer, C. (1993). The role of deliberate practice in the acquisition of expert performance. Psychological Review, 100, 363-406.

15. Gentner, D., Rattermann, M., Forbus, K. (1993). The role of similarity in transfer. Cognitive Psychology, 25, 524-575.

16. Gick, M., \& Holyoak, J. (1987). The cognitive basis for knowledge transfer. In S. Cormier and J.Hagman (Eds.), Transfer of learning (pp. 9-46). San Diego, CA: Academic Press.

17. Hewson, P. W., \& Hewson, M. G. A. (1984). The role of conceptual conflict in conceptual change and the design of science instruction. Instructional Science, 13, $1-13$.

18. Holyoak, K. J., \& Thagard, P. (1995). Mental leaps. Cambridge, MA: Cambridge University Press.

19. Karmiloff-Smith, A. (1992). Beyond modularity: A developmental perspective on cognitive science. Cambridge, MA: MIT Press.

20. McCloseky, (1983). Intuitive theories of motion. In D. Gentner \& A. L. Stevens, (Eds.), Mental models (pp. 299-323). Hillsdale, NJ: Erlbaum.

21. Nussbaum, J. (1985). The Earth as a cosmic body. In R. Driver, E. Guesne, \& A. Tiberghien (Eds.), Children's ideas in science (pp.170-192). Milton Keynes, UK: Open University Press.

22. Ohlsson, S. (1995a). Learning to do and learning to understand: A lesson and a challenge for cognitive modeling. In P. Reimann and H. Spada, (Eds.), Learning in humans and machines: Towards an interdisciplinary learning science. Oxford, UK: Elsevier.

23. Piaget, J. (1985). The equilibration of cognitive structures. Chicago, IL: The University of Chicago Press.

24. Reber, A. (1993). Implicit learning and tacit knowledge. New York: Oxford University Press.

25. Resnick, L. B., \& Omanson, S. (1987). Learning to understand arithmetic. In R. Glaser, (Ed.), Advances in instructional psychology (Vol. 3, pp. 41-95). Hillsdale, NJ: Erlbaum.

26. Salzman, M., Dede, C., Loftin, R., \& Chen, J. A. (1998)A model for understanding how virtual reality aids complex conceptual learning. Presence (in press).

27. Singley, M., \& Anderson, J. R. (1989). The transfer of cognitive skill. Cambridge, MA: Harvard University Press.

28. Sternberg, R. J., (Ed.), (1984). Mechanisms of cognitive development. New York: W. H. Freeman.

29. Vosniadou, S. (1994). Capturing and modeling the process of conceptual change. Learning and Instruction, $4,45-69$. 
30. Vosniadou. S., \& Brewer, W. F. (1994). Mental models of the day/night cycle. Cognitive Science, 18, 123-183.

31. Youngblut, C. (1998) Educational uses of virtual reality technology. Technical Report IDA Document D-2128, Institute for Defense Analyses, Alexandria, VA.

\section{APPENDIX: INTERVIEW QUESTIONS}

1 . Which way is "up" (for you)? Which way is "down" (for you)? Is up and down always that way?

2. Which way is "down" for people in China? If you were pointing up and someone in China were pointing up, would you be pointing in the same direction?

3. Draw a picture of the Earth.

4. Show where people live (on your drawing).

5. Can people see things that are very far away?

6. If we shoot a cannon ball from here to Australia/China, can we see where it lands? If now, why not? (Draw a picture.)

7. If you jump into an airplane and fly in the same direction (at the same height) for a very long time, how far could you go? Where would you end up if you just kept going and going?

8. Would you ever come back to where you started? (If yes, please draw a picture.)

9. Would you ever get to the end of the Earth? If yes, what does the end look like? If no, why does the Earth have no end?

10. Could you/an animal accidentally fall off the Earth? If yes, how would that happen? To where would you fall? If no, why not?

11. With regard to the child's drawing of the Earth, ask: "What is here?" while pointing to the region on the side of the drawing. If yes, what is here?

12. Show where the moon is (on the Earth drawing). Can the moon be anywhere else?

13. Where is the moon during the day when we cannot see it?

14. Draw a sunset. Why is the sun disappearing? Why can't we see it during the night? Where does it go?
15. With regard to the following drawing: What happens if you put the balls in the "other" baskets/let go of the balls?
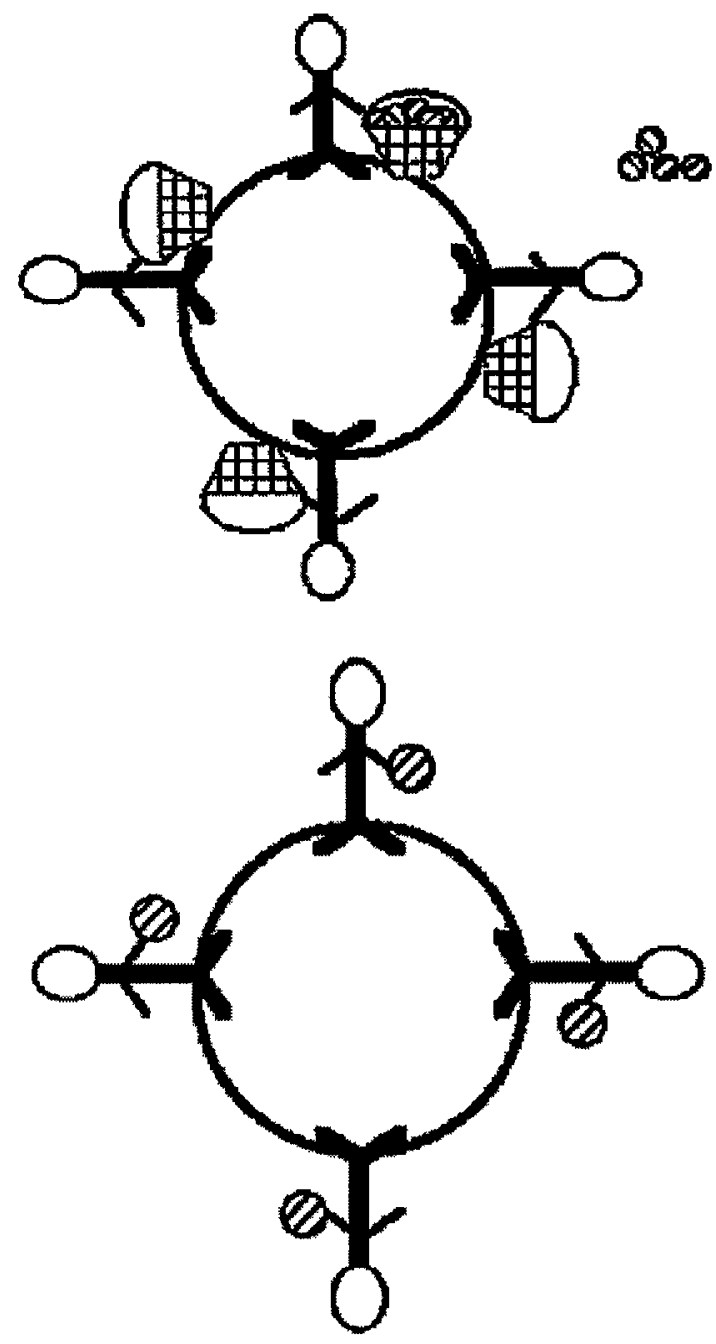

16. In these pictures of the Earth, a shaft has been drilled all the way through. What happens when the persons lets go of the ball?
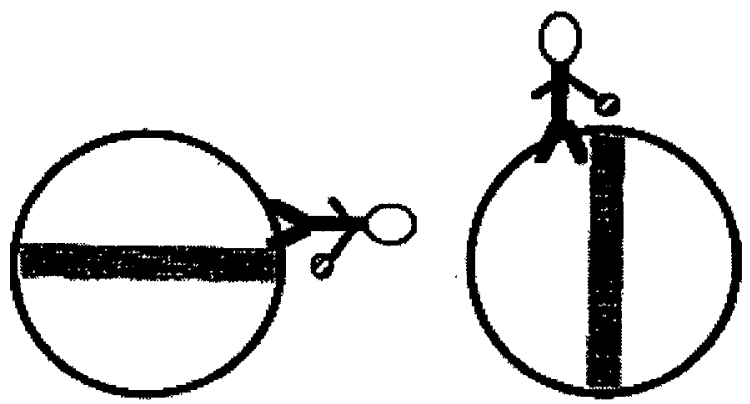